Print ISSN: 2735-4121 Online ISSN : 2735-413X

\title{
Effect of Structured Cardiopulmonary Resuscitation Training Program on Nursing' Competence
}

Jehan Sayyed Ali Sayyed(1) Reda Mohamed El-Sayed Ramadan(2) Eman Sobhy Elsaid Hussein(2,4)

\& Nehal Abd Elazim Youssef Abd ELmeguid(3)

(1) Professor of Medical-Surgical Nursing, Faculty of Nursing, Minia University. Egypt.

(2) Medical-Surgical Nursing, Faculty of Nursing, Ain Shams University. Egypt.

(3) Lecturer of Nursing Department, College of Applied Medical Sciences at Al Quwayiyah, Shaqra

University, $K S A$.

(4) Nursing Department, Applied Medical Science, Taibah University, KSA.

E.mail of corresponding author: relsayed@su.edu.sa

\begin{abstract}
Background: Cardiopulmonary resuscitation training is mandatory for nursing staff, whereas the ability to respond quickly and effectively to a cardiac arrest situation rests on nursing competence. Aim: to evaluate the effectiveness of structured cardiopulmonary resuscitation training program on nursing' competence. Subjects\& Methods: A quasiexperimental design was used to fulfil the aim of the study. Subjects: A convenience sample of 60 critical care nurses who were recruited from critical care units. Study setting: This study was carried out at five critical care units affiliated to Minia University Hospitals, Egypt. Tools of data collection: were; First Tool: "Structured Questionnaire" it consists of (two parts): Part I: Nurses' personal data such as age, and gender; Part II: Nurses' knowledge assessment about resuscitation process and its role in resuscitation, Second Tool: Observational checklist for assessment nurses' performance of resuscitation. Results: There was a highly statistically significant difference in critical care nurses' knowledge and performance pre- and post- structured cardiopulmonary resuscitation training program. also, there was no statistically significant correlation between all personal characteristics for studied nurses and their total performance score pre- and post- structured cardiopulmonary resuscitation training program except in a studied sample's age categories. Conclusion: Improvement was obvious in the level of knowledge and performance of CPR of critical care nurses under study after attending structured cardiopulmonary resuscitation training program. Recommendation: Structured CPR training program should be available to train critical care nurses.
\end{abstract} program.

Keywords:Cardiopulmonary resuscitation, Nursing' competence, Structured training 


\section{Introduction}

Cardiac arrest represents a dramatic event that can occur suddenly and often without premonitory signs, characterized by sudden loss of consciousness and breathing after cardiac output ceases and both coronary and cerebral blood flows stop. Restarting of the blood flow by cardiopulmonary resuscitation (CPR) potentially reestablishes some cardiac output and organ blood flows. CPR has the potential of re-establishing spontaneous circulation, often in conjunction with electrical defibrillation, but CPR is likely to be successful only if it is instituted within 5 minutes after the heart stops beating (Ristagno, Gullo et al. 2006).

Cardiopulmonary resuscitation (CPR) is a series of life-saving actions that improve the chances of survival, following cardiac arrest. Successful resuscitation, following cardiac arrest, requires an integrated set of coordinated actions represented by the links in the Chain of Survival (Lee 2012). Cardiopulmonary resuscitation (CPR) consists of the use of chest compressions and artificial ventilation to maintain circulatory flow and oxygenation during cardiac arrest (Bon 2020).

The World Health Organization indicates the cardiovascular diseases (CVD's) account for $46 \%$ of total deaths in Egypt; CVD's are a major public health concern with significant social and economic implications in terms of healthcare-needs, lost productivity and premature death (Choksey 2018).

A comprehensive, structured, integrated, multidisciplinary system of care should be implemented in a consistent manner for the treatment of post-cardiac arrest care patients. The return to a prior quality and functional state of health is the ultimate goal of a resuscitation system of care (Lee 2012).

The evidence is secure that the quality of chest compressions is a major determinant of successful resuscitation (Ristagno, Tang et al. 2007) and major effect on outcomes (Wik, KramerJohansen et al. 2005). Rapid-response systems evolved concurrently and emergency medical personnel, especially, were comprehensively trained in life-support interventions (Giuseppe Ristagno, Wanchun Tang et al. 2009)

Effective education is a key variable in improving survival outcomes from cardiac arrest. Without effective education, lay rescuers and healthcare providers would struggle to consistently apply the science supporting the evidence-based treatment of cardiac arrest (Magid, Aziz et al. 2020). Evidence-based instructional design is critical to improving provider performance and patient-related outcomes from cardiac arrest. Instructional design features are the active ingredients, the key elements of resuscitation training programs that determine how and when content is delivered to nurses (Morley, Atkins et al. 2020)

In the 2020 Guidelines, we provide recommendations about various instructional design features in resuscitation training and describe how specific provider considerations influence resuscitation education. Here, we highlight new and updated recommendations in education that we believe will have a significant impact on outcomes from cardiac arrest (AHA. American Heart Association 2020).

Nurses played three major roles in cardiopulmonary resuscitation (CPR), bedside first responder, resuscitation 
team member, and clinical or administrative leader (Guetterman, Kellenberg et al. 2019)Training of nurses has an impact on the efficiency and outcome of cardiopulmonary resuscitation (CPR), and thus, assessment of CPR knowledge among undergraduate nurses is very important to improve training program (Vural, Koşar et al. 2016)The nursing training should play more emphasis on the nurses to learn about different techniques of CPR. This is essential for working in hospital settings (Mohamed 2017).

\section{Magnitude of the problem}

CPR training is necessary for nurses in order that they acquire the capabilities to respond rapidly and accurately, so cardiopulmonary resuscitation education in actual clinical spaces can be used to enhance learning outcomes and improve nursing performance.

\section{Aim of the study:}

The aim of the current study was to evaluate the effectiveness of structured cardiopulmonary resuscitation training program on nursing' competence.

\section{Research Hypothesis:}

H (1). Nurses' knowledge about cardiopulmonary resuscitation process will be better than pre structured cardiopulmonary resuscitation training program.

H (2). Nurses' performance about cardiopulmonary resuscitation process will be better than pre structured cardiopulmonary resuscitation training program.

\section{Materials and Methods:}

Research Design: The quasiexperimental design was utilized to achieve the aim of the current study.

Study setting: This study was conducted at the critical Care units affiliated to Minia University Hospital including (Intensive Care Unit, Emergency unit, Cardiothoracic Care Unit, Cardiac Care Unit, Stroke) in Minia Governorate, Egypt.

\section{Sampling:}

A convenience sample of 60 critical care nurses who were recruited after their acceptance to participate in the study from the setting which mentioned before. Nurses who refused participation in the study were excluded from the study. The sample size was estimated with STATA 10 program.

Tools for data collection:

Two tools were used to collect the data by the researchers as the following:

First Tool: "Structured

Questionnaire" it consists of (two parts):

- 1 resuscitation. It was consisted of 38 multiple choice questions translated into Arabic language in order to assess nurses' level of knowledge pre/post structured cardiopulmonary resuscitation training program implementation. The reliability test was done whereas Cronbach's Alpha equal 0.81.

\section{Scoring System:}

Each right answer takes one grade and the wrong answer takes zero grade with a total scores 38 .

The total score was divided into two categories as follows:

- Less than $60 \%$ was graded as unsatisfactory knowledge.

- More than or equal $60 \%$ was graded as satisfactory knowledge.

Second Tool: Observational checklist for assessment nurses' performance of resuscitation

It was developed by the researcher after reviewing the related literature to assess nurses' performance regarding their roles during resuscitation for critically ill patients at different 
critical care units before and after structured resuscitation training regarding to its role during chest compression, ventilation, drug administration, and recording. This checklist consists of 23 items. The reliability test was done whereas Cronbach's Alpha equal 0.79 (Sayed, Youssef et al. 2015) \&(Feroze, Afzal et al. 2017).

\section{Scoring System:}

Checklists' scores were distributed according to the weight and importance of each step. A total step grade would be given if it is correctly done. Zero would be given if it isn't done or incorrectly done.

\section{into three levels:}

The scoring system was divided

- $\quad \% \vee \cdot \geq$ graded as poor performance.

- $<70-85 \% \%$ graded as faire performance.

- $\quad>85 \%$ graded as good performance.

Tools validity:

The study tools were developed after reviewing the related literature. To determine content and face validity, these tools were tested by a Jury committee that consists of five medical surgical-nursing professor experts. Recommendations were followed; the questions that were not appropriate were taken out and some questions needed clarification and modifications were done.

Pilot study:

A pilot study was conducted to assess the applicability of the instruments, the feasibility of the study and to estimate the time needed for data collection. It was conducted on $10 \%$ of the total participants. Based on the results of the pilot study, no refinement/ modifications were done for data collection instruments. All nurses who shared in the pilot study were included in the study.

Fieldwork:

This study was carried out through three consecutive phases: Preparatory phase, implementation phase and evaluation phase.

\section{- Preparatory phase:}

To carry out the study, ethical approval was obtained from the Scientific Research Ethical Committee of Minia University. Official letters were issued to the hospital director and nursing director of Minia University Hospital from the faculty of nursing explaining the aim of the study to obtain permission for the collection of data.

The data collection period was for five months, starting from February to July 2019. The researchers explained the nature \& purpose of the study and pre-training data (pre-test) collected through four weeks within 60-90 minutes to test studied sample for actual level of knowledge and performance of cardiopulmonary resuscitation process.

\section{Implementation phase:}

In this phase, the total number (60) of the study participants was divided into twenty classes each class consists of three participants. The appointment for starting training sessions was scheduled with the study sample according to their circumstances. The training program was conducted as one session for knowledge as the following nurse's role in resuscitation, component of CPR, DC shock in CPR, medication in CPR and crush cart. Two sessions for practice for every class; each session took about 3045 minutes. At the end of sessions (knowledge \& performance), the researchers gave the study participants brochure as an educational tool about resuscitation process: It was formulated by the researchers after extensive 
literature review by professors' experts in the field of critical care nursing, and translated into the Arabic language with figures for more clarification.

\section{Evaluation phase:}

This phase was emphasized on estimating the effectiveness of structured cardiopulmonary resuscitation training program on nursing' competence. Each nurse was reassessed by the researchers immediately and after three months after the first assessment (knowledge and performance of CPR).

\section{Ethical Considerations:}

Official permission to conduct the study was requested and obtained from the authoritative committee personal. Nurses who voluntarily agreed to be involved in the study; following a thorough explanation of the purpose of the study. Informed oral consent was obtained from each nurse. Also, nurse

\section{Results:}

Table (1): Socio-demographic characteristic of the studies group, $n=60$.

\begin{tabular}{|c|c|c|}
\hline Socio-demographic characteristic & No. (60 nurses) & $\% 1 \ldots$ \\
\hline \multicolumn{3}{|l|}{ Age categories } \\
\hline $20 \geq 25$ & 31 & 51.7 \\
\hline $25<30$ & 7 & 11.6 \\
\hline$\geq 30$ & 22 & 36.7 \\
\hline Mean \pm SD & \multicolumn{2}{|c|}{$27.88 \pm 7.7$ years } \\
\hline \multicolumn{3}{|l|}{ Gender } \\
\hline Male & 19 & 31.7 \\
\hline Female & 41 & 68.3 \\
\hline \multicolumn{3}{|l|}{ Educational Level } \\
\hline Bachelor & 9 & 15 \\
\hline Technical institute & 33 & 55 \\
\hline Diploma \& secondary school & 18 & 30 \\
\hline \multicolumn{3}{|l|}{ Years of experience in ICU } \\
\hline$<5$ years & 36 & 60 \\
\hline$\geq 5$ years & 24 & 40 \\
\hline Mean \pm SD & \multicolumn{2}{|c|}{$5.26 \pm 2.65$ years } \\
\hline \multicolumn{3}{|c|}{ Previous workshop attendance or training courses } \\
\hline Yes & 14 & 23.3 \\
\hline No & 46 & 76.7 \\
\hline
\end{tabular}

was assured that they could withdraw from the study at any time, without penalty, if they so wished. Nurses were allowed to ask questions. It was also explained that the study findings would be disseminated in the form of presentations at conferences and publication in an accredited journal. Confidentiality and anonymity of each subject were assured through coding of all data.

\section{Statistical analysis}

The collected data were scored, tabulated and analyzed using (SPSS) version 20. The collected data were presented in tables and graphs using the actual numbers and percentages. Appropriate statistical tests were used to analyze the data as, chi-square test $\left(\mathrm{X}^{2}\right)$, independent sample t-test. The level of significance was set at $\mathrm{p}<0.05$. 
Table (I) demonstrates that more than half of the study group's age $51.7 \%$ was between $20-25$ years and their mean average age was $(27.88 \pm 7.70)$ years and the highest percentage from them constituted $(68.3 \%)$ were females, also as regards their educational level results found that more than half among them $55 \%$ had graduated from technical institute degree in nursing. On the other hand, the highest percentage of participants constituted $60 \%$ had less than five years of experience in working at critical units, but lowest percentage of them were more than five years of experience and their mean average was $5.26 \pm 2.65$ years. Finally, as regards, previous workshop attendance regarding cardiopulmonary resuscitation process results revealed that the majority of the study group constituted $76.7 \%$ hadn't attended any previous workshop or training courses.

Fig.1.ffect of structured cardiopulmonary resuscitation training program on nursing' level of knowledge, $n=60$.

Figure (1): revealed that $78.3 \%$ of studied group had unsatisfactory knowledge during pre- structured cardiopulmonary resuscitation training program, while $100 \%$ of them had a satisfactory knowledge level immediately post structured cardiopulmonary resuscitation training program, while post structured cardiopulmonary resuscitation training program (after three months) $93.3 \%$ of them had satisfactory knowledge level.

Fig.2. Percentage distribution of the nurses under study as regards their level of performance CPR process pre- and post- structured cardiopulmonary resuscitation training program, $n=60$.

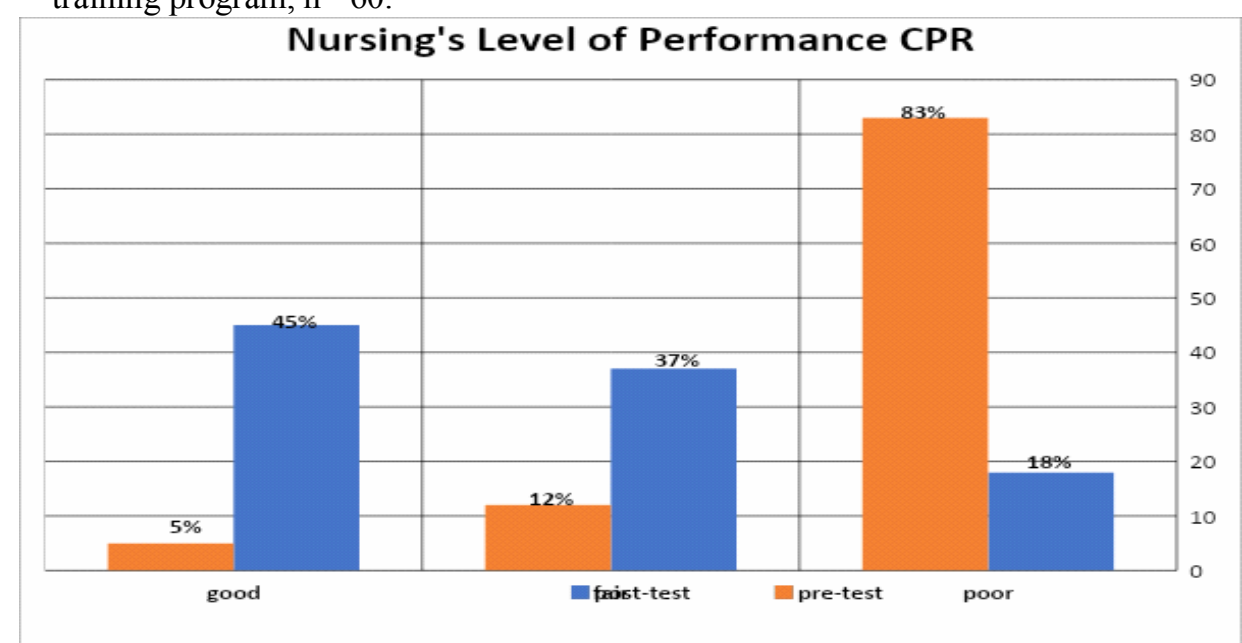

Figure (2): The figure shows that $83 \%$ of studied group had poor performance level during pretest, while
$45 \%$ of them had good practice level post three months test. 
Table (2): Correlations between knowledge and performance among studied sample pre $\&$ post structured cardiopulmonary resuscitation training program, $\mathrm{n}=60$.

\begin{tabular}{|cc|c|c|c|c|}
\hline \multicolumn{3}{|c|}{ Knowledge } & \multicolumn{2}{c|}{$\begin{array}{c}\text { Pre structured CPR } \\
\text { training program }\end{array}$} & \multicolumn{2}{|c|}{$\begin{array}{c}\text { Post structured CPR } \\
\text { training program }\end{array}$} \\
\cline { 4 - 6 } & & $\mathbf{R}$ & $\boldsymbol{P}$ & $\mathbf{R}$ & $\boldsymbol{P}$ \\
\hline $\begin{array}{c}\text { Pre structured CPR training } \\
\text { program }\end{array}$ & & 0.310 & $.016^{*}$ & -0.822 & $.000^{* *}$ \\
\hline $\begin{array}{l}\text { Post structured CPR training } \\
\text { program }\end{array}$ & -0.136 & $.300(\mathrm{NS})$ & 0.618 & $.000^{* *}$ \\
\hline
\end{tabular}

Table (2): Showed that there was highly statistical significance difference between knowledge and performance at pre \& post-structured cardiopulmonary resuscitation training program after three months.

Table (3): Correlations between personal data and performance among studied sample pre $\&$ post structured cardiopulmonary resuscitation training program, $n=60$.

\begin{tabular}{|c|c|c|c|c|}
\hline \multirow[t]{2}{*}{ Personal data } & \multicolumn{2}{|c|}{$\begin{array}{c}\text { Pre- structured CPR training } \\
\text { program }\end{array}$} & \multicolumn{2}{|c|}{$\begin{array}{c}\text { Post -structured CPR } \\
\text { training program }\end{array}$} \\
\hline & $\mathbf{R}$ & p-value & $\mathbf{R}$ & p-value \\
\hline Age categories & 0.063 & $.630(\mathrm{NS})$ & -.253 & $.052 *$ \\
\hline Gender & -0.091 & $.487(\mathrm{NS})$ & 0.077 & $.560(\mathrm{NS})$ \\
\hline Education level & 0.079 & $.550(\mathrm{NS})$ & $\begin{array}{c}- \\
0.033\end{array}$ & $.800(\mathrm{NS})$ \\
\hline $\begin{array}{l}\text { - Years of experience in working at } \\
\text { critical units }\end{array}$ & -0.082 & $.534(\mathrm{NS})$ & 0.037 & $.776(\mathrm{NS})$ \\
\hline $\begin{array}{l}\text { Previous workshop attendance } \\
\text { regarding resuscitation process }\end{array}$ & -0.067 & $.611(\mathrm{NS})$ & -.047 & $.722(\mathrm{NS})$ \\
\hline
\end{tabular}

Table (3) showed that there was no statistically significant correlation between all personal characteristics for studied nurses and their total performance score pre- and poststructured CPR training program except in a studied sample's age categories it had a significant correlation with mean practice score after three months post structured CPR training program.

\section{Discussion:}

In hospitals worldwide, it is usually the nurse who discovers a cardiac arrest (loss of consciousness, absence of pulse and breathing) and initiates the procedure of CPR. Nurses need to know the skills and theories behind CPR as performing quality CPR might improve the patient's chance of survival and increase the opportunity of recovery, thus, nurse's competency in CPR is a critical factor in determining successful patient outcomes from a cardiac arrest (Marzooq and Lyneham 2009). In addition, nurses should exhibit the knowledge and skills necessary in an emergency to help sustain life until medical help arrives. Nurses are usually the first to respond at the scene of a cardiac arrest and their ability to provide care might well be critical to the successful outcome of a resuscitation attempt (Lee 2005).

The findings of this study revealed that the mean age was $27.88 \pm$ 7.709 years. This might be related to the desire of university's hospitals to provide hospitals with nurses' young so that they have the ability for arduous critical care work.

In the present study, more than two thirds of the total study groups were females. This finding was in accordance with (Selman and Sabah 2018) who 
founded that, during the study on critical care nurses the female is the dominant gender among the current study. This might be due to the fact that nursing is a universal feminine profession especially in our society culture as well as the enrolment of the male students in this profession was started in the late decades.

One of the noticeable finding in this study is that more than half of the study sample graduated from a technical institute. This finding agreed with (Eubayd and Abbas 2017) who reported that two fifths of the studied group were from nursing clinical institute. This might be attributed to the small number of college graduates who have desire to work at university hospitals.

Regarding years of experience of study participants, more than half of the studied groups had less than five years of experience in working at critical units. This might be due to the fact that they were newly graduated and young aged. This result contradicting with (Rajeswaran, Cox et al. 2018) who mentioned that work experience for less than half of critical care nurses were from between 1 and 6 years and more than half of them were for more than 7 years.

The current study result revealed that the most of the study sample had not attended any previous workshop regarding cardio pulmonary resuscitation process (CPR). This finding is corresponding with (Aljanabi, Nursing et al. 2014) who stated that less than two thirds of critical care nurses had no previous workshop attendance regarding CPR. This might be due to that there is no preparatory program for new nurses and lack of interest from critical care nurses to attend conferences or workshops.
As regards critical care nurses ' knowledge about CPR, the present study findings revealed that more than two thirds of critical care nurses had unsatisfactory knowledge pre training program, while most of them had satisfactory knowledge level post training program. This difference in knowledge found in the present study might be related to the knowledge acquired from the structured CPR training program. This finding was parallel with (Tíscar-González, BlancoBlanco et al. 2019) who reported that, nurses who received educational program had improvement of knowledge.

In relation to performance of CPR, the present study result documented that, less than one tenth of critical care nurses had good performance pre structured CPR training program regarding to $\mathrm{CPR}$ while more than two fifths of them had good performance post structured CPR training program. This difference in performance found among the critical care nurses under study might be related to the skills acquired from structured CPR training program especially that there was no significant previous training or attendance any workshop. This finding was supported by (Munezero, Atuhaire et al. 2018) who found that nurses' skills after training was improved from less than half of nurses pre training to majority of them post training.

In relation to correlations between critical care nurses' knowledge and their performance of CPR pre/post structured CPR training program implementation, the present study result indicated that there was highly statistical significance between knowledge and performance at pre/post structured CPR training program implementation. This finding is not corresponding with (Elazazay, 
Abdelazez et al. 2012) who reported that decreasing knowledge level at the preliminary baseline data assessment for nurses in intensive care unit that also reflected in the nurses' practice at preintervention of the program, that converted to a significant improvement of both knowledge and practice after intervention.

Regarding correlations between personal data of critical care nurses under study and their performance of CPR pre/post structured CPR training program implementation, the present study results documented that there was no statistically significant correlation between personal data of study group and their performance of CPR pre/post structured CPR training program implementation except age it had a significant correlation with mean performance after structured CPR training program implementation. These results contradicting with (Rajeswaran, Cox et al. 2018) who mentioned that male participants scored slightly better than female counterparts in the pre-test, also, the highest improvement realized (more than one quarter) was observed among the participants with five to six years of experience and the least improvement (less than one quarter) was among the participants who have more than eleven years of experience.

\section{Conclusions:}

\section{The present study concluded that:}

Improvement was obvious in the level of knowledge and performance of CPR of critical care nurses under study after attending the structured CPR training program.

\section{Recommendations}

Taking into consideration the results of this study, it is highly recommended that:

- Training program should be organized for critical care nurses about CPR with updating CPR techniques

- $\quad$ Structured CPR training program should be available to train critical care nurses.

- $\quad$ Repetitive CPR training program to ensure that critical care nurses are competent in the event of a cardiac arrest.

- Further studies are needed to determine factors influencing CPR performance.

\section{References:}

- AHA. American Heart Association (2020). "American Heart Association (AHA) Guidelines for Cardiopulmonary Resuscitation (CPR) and Emergency Cardiovascular Care (ECC)." $\quad$ https://cpr.heart.org//media/cpr-files/cpr-guidelinesfiles/highlights/hghlghts 2020 ec c guidelines english.pdf.

- Aljanabi, M., M. Nursing, B. Amin and J. Al-Ani (2014). "Assessment of Nurses' Knowledge towards Cardiopulmonary Resuscitation at Al-Najaf City's Teaching Hospital. . Kufa Journal for Nursing Sciences 4.

- Bon, C. A. (2020). "Cardiopulmonary Resuscitation (CPR) https://reference.medscape.com/(S ep 15, 2020).

- Choksey, R. (2018). "Pedal it out to bring Egypt's heart beat back." Philips .News center $\mid$ Egypt(Sep 19, 2018): 
https://www.philips.com.eg/aw/about/news/archive/standart/ne ws/press/2018/20180919-pedal-itout-to-bring-egypt-s-heart-beatback.html.

- $\quad$ Elazazay, H. M., A. L. Abdelazez and O. A. Elsaie (2012). Effect of Cardiopulmonary Resuscitation Training Program on Nurses Knowledge and Practice, Life Sci J.

- $\quad$ Eubayd, A. and S. Abbas (2017). "Effectiveness of an Educational Program on Nurses Knowledge Concerning Cardiopulmonary Resuscitation at lmam Hussein Medical City in Holy Kerbala'a Governorate." Journal of Integrated Health Science 6.

- Feroze, M., M. Afzal, H. Sarwar, S. Gilani and S. Afshan (2017). "Assess Knowledge and Practice of Registered Nurses about Patient Safety after Cardiac Catheterization in Punjab Institute of Cardiology Hospital, Lahore." Pakistan Journal of Medical and Health Sciences 2.

- Giuseppe Ristagno, Wanchun Tang and Max HarryWeil (2009). "Cardiopulmonary Resuscitation: From the Beginning to the Present Day." Elsevier Inc.

- Guetterman, T. C., J. E. Kellenberg, S. L. Krein, M. Harrod, J. L. Lehrich, T. J. Iwashyna, S. L. Kronick, S. Girotra, P. S. Chan and B. K. Nallamothu (2019). "Nursing roles for in-hospital cardiac arrest response: higher versus lower performing hospitals." BMJ Qual Saf 28(11): 916-924.

- $\quad$ Lee, K. (2012). "Cardiopulmonary Resuscitation: New Concept."
Tuberculosis and respiratory diseases 72: 401-408.

- Lee, M. H. (2005). "The effect of CPR training on the knowledge and attitude of laypersons." ( Unpublished master's thesis,): Chonnam National University, Gwangju..

- Magid, D. J., K. Aziz, A. Cheng, M. F. Hazinski, A. V. Hoover, M. Mahgoub, A. R. Panchal, C. Sasson, A. A. Topjian, A. J. Rodriguez, A. Donoghue, K. M. Berg, H. C. Lee, T. T. Raymond and E. J. Lavonas (2020). "Part 2: Evidence Evaluation and Guidelines Development: 2020 American Heart Association Guidelines for Cardiopulmonary Resuscitation and Emergency Cardiovascular Care." Circulation 142(16_suppl_2): S358-S365.

- Marzooq, H. and J. Lyneham (2009). "Cardiopulmonary resuscitation knowledge among nurses working in Bahrain." International journal of nursing practice 15: 294-302.

- $\quad$ Mohamed, E. A. (2017). "Effect of Cardiopulmonary Resuscitation (CPR) Trainingprogram on knowledge and practices of Internship TechnicalInstitute of nursing students." IOSR Journal of Nursing and Health Science (IOSR-JNHS). May - June 2017. 6(3): 73-81.

- Morley, P. T., D. L. Atkins, J. C. Finn, I. Maconochie, J. P. Nolan, Y. Rabi, E. M. Singletary, T.-L. Wang, M. Welsford, T. M. Olasveengen, R. Aickin, J. E. Billi, R. Greif, E. Lang, M. E. Mancini, W. H. Montgomery, R. W. Neumar, G. D. Perkins, J. Soar, M. H. Wyckoff and L. J. Morrison 
Effect of Structured Cardiopulmonary etc...

(2020). "Evidence Evaluation Process and Management of Potential Conflicts of Interest: 2020 International Consensus on Cardiopulmonary Resuscitation and Emergency Cardiovascular Care Science With Treatment Recommendations." Circulation 142(16_suppl_1): S28-S40.

- $\quad$ Munezero, J. B. T., C. Atuhaire, S. Groves and S. N. Cumber (2018). "Assessment of nurses knowledge and skills following cardiopulmonary resuscitation training at Mbarara Regional Referral Hospital, Uganda." The Pan African medical journal 30: 108-108.

- $\quad$ Rajeswaran, L., M. Cox, S. Moeng and T. Billy (2018). "Assessment of nurses' cardiopulmonary resuscitation knowledge and skills within three district hospitals in Botswana." African Journal of Primary Health Care \& Family Medicine 10.

- Ristagno, G., A. Gullo, W. Tang and M. H. Weil (2006). "New cardiopulmonary resuscitation guidelines 2005: importance of uninterrupted chest compression." Crit Care Clin 22(3): 531-538, x.

- Ristagno, G., W. Tang, Y. T. Chang, D. B. Jorgenson, J. K. Russell, L. Huang, T. Wang, S. Sun and M. H. Weil (2007). "The quality of chest compressions during cardiopulmonary resuscitation overrides importance of timing of defibrillation." $\underline{\text { Chest }}$ 132(1): 70-75.

- Sayed, Y. E., W. Youssef, H. A. Alshekhepy and H. Elfeky (2015).
"Nurses' Knowledge and Practices regarding Detaction and Management of Acute Drug Poisoning at Cairo University Hospitals." Egyptian Journal of Nursing, 10(1).

- Selman, F. and A. Sabah (2018). "Effectiveness of an educational program on nurses' practices concerning nursing interventions for patients with coronary artery disease in AL-Nasiriyah Heart Center." Indian Journal of Public Health Research \& Development 9: 1262 .

- Tíscar-González, V., J. BlancoBlanco, M. Gea-Sánchez, A. Rodriguez Molinuevo and $\mathrm{T}$. Moreno-Casbas (2019). "Nursing knowledge of and attitude in cardiopulmonary arrest: crosssectional survey analysis." PeerJ 7: e6410.

- Vural, M., M. Koşar, O. Kerimoğlu, F. Kızkapan, S. Kahyaoğlu, S. Tuğrul and $\mathrm{H}$. İşleyen (2016). "Cardiopulmonary resuscitation knowledge among nursing students:A questionnaire study." Anatolian journal of cardiology 17.

- Wik, L., J. Kramer-Johansen, H. Myklebust, H. Sørebø, L. Svensson, B. Fellows and P. A. Steen (2005). "Quality of cardiopulmonary resuscitation during out-of-hospital cardiac arrest." Jama 293(3): 299-30 